\title{
LXVII. Note on thermal electrolysis
}

\section{J.H. Gladstone F.R.S. \& Alfred Tribe}

To cite this article: J.H. Gladstone F.R.S. \& Alfred Tribe (1881) LXVII. Note on thermal electrolysis, Philosophical Magazine Series 5, 11:71, 508-510, DOI: 10.1080/14786448108627052

To link to this article: http://dx.doi.org/10.1080/14786448108627052

曲 Published online: 08 Jun 2010.

Submit your article to this journal $\pi$

Џ Article views: 2

Q View related articles 두 
the incongruence between the degree of convergence and the parallax of motion is perceived with great accuracy.

The easiest way to see them is the following :-Look to a papered wall, the pattern of which is regularly repeated at distances not much greater than the distance between your eyes (between 60 and 70 millim.). You know that it is possible to make your eyes converge either to a nearer or to a more distant point than the surface of the paper; so that in your binocular field of vision two images get corresponding position, which do not belong to the same part of the paper, but to two different copies of the pattern. You see, then, a stereoscopic image of the pattern, either more distant and of greater apparent size, if you diverge your eyes, or nearer and smaller, if you converge. But the appreciation of the apparent distance of this pattern is not very precise. If you try to bring a pencil to the apparent place of the nearer pattern, you will find that the point of convergence is far nearer than the apparent place of the pattern.

When you now move your head the pattern moves also. If you have increased the convergence of the eyes, the pattern moves with the eyes, 'as well to the left and the right as up and down and forwards and backwards. If you diverge, it goes in opposite direction to your head.

LXVII. Note on Thermal Electrolysis. By J. H. Gladstone, F.R.S., and Alfred Tribe* .

D URING the course of our experiments on metallic replacements we noticed that some sheet silver, immersed in fused silver chloride, became quickly studded with crystals of metal. A replacement of a metal by itself seemed so anomalous, that our first idea was that the silver employed contained certain impurities; but we found that the action took place just as well with the purest silver we could obtain, and that it was not restricted to the substances above mentioned. Not only might the iodide of silver be substituted for the chloride with the same result, though not so rapidly effected, but other metals might be employed. Thus, when copper was immersed in fused cuprous chloride, crystals of that metal separated; and similar exchanges took place when zinc was placed in melted zinc chloride, or iron in ferrous chloride in a molten condition.

It was then thought that a different physical condition

* Communicated by the Physical Society, having been read at the Meeting on April 9, 
of the rolled metals might give rise to the action; but this was disproved by the following experiments :-

Some crystals of silver prepared by electrolysis were placed in the open end of a piece of glass tubing slightly constricted, and then immersed in silver chloride heated in a crucible by a Bunsen lamp. In about half an hour the crystals were found to have grown in a net-like mass from their original position to a point about half an inch higher in the tube. This experiment was repeated with crystals of silver which had themselves been deposited from the fused chloride by means of metallic silver. A similar result was obtained.

We were then led to the conclusion that the change depended upon the unequal heating of different parts of the immersed metal, or rather of the salt in which it was immersed. It is evident that upon the contact theory of voltaic action, there will be a difference of potential between the metal and the liquid chloride with which it is in contact; and it is in accordance with analogy to suppose that this difference of potential will vary according to the temperature. Now, under the conditions of the oxperiment, it cannot be supposed that all parts of the fused chloride in contact with the immersed metal were always equally heated; and we have therefore the possibility of a current being established with the consequent electrolysis of the salt.

In order to test this view, some silver chloride was fused in a hard glass tube and a rod of silver placed in the liquid. On heating the underside of the lower end for 10 minutes, we found a considerable crop of silver crystals in the comparatively cool part of the fluid.

In another experiment some silver chloride was fused in a crucible, and one side of the vessel was more strongly heated than the other. Two long rods of silver were connected with a galvanometer and placed, one in the hotter, the other in the colder part of the chloride. The latter was found studded with crystals at the end of 15 minutes, whilst the former was quite clean. On repeating this experiment, it was always found that the galvanometer gave a larger deflection the greater the difference of temperature between the portions of the fused mass penetrated by the silver wires, and that the current was reversed with a reversal of the rods. Copper wires in cuprous chloride gave similar results.

In an experiment with an electrometer we obtained a clear indication of a difference of potential between silver rods in hotter and colder parts of silver chloride fused in a small crucible, the deflection showing a difference of possibly $\frac{1}{50}$ of a Phil. Mag. S. 5. No. 71. Suppl. Vol. 11. 
volt. The reversal of the rods again produced a reversal of the deflection.

In corroboration of the theory above stated, it should be borne in mind that the chlorides of silver, copper, zinc, and iron, when fused, are electrolytes. The liquid chloride of tin is not an electrolyte ; and it was found that on immersing tin in this liquid no deposition of erystals was observed when it was so arranged that one part of the liquid was kept at the heat of boiling water and another at the ordinary temperature for two days; nor was there the least action on a galvanometer when arrangements were made for testing by that instrument.

These experiments form a good lecture-table illustration of the conversion of heat into electricity and chemical force. They also seem to have a bearing on the theory of voltaic action, since, from the nature of the substances employed, it is difficult to imagine that chemical action in any way initiates the current.

LXVIII. Upon the Production of Sound by Radiant Energy. By Alexander Graham BelL *.

[Plates X. \& XI.]

TN a paper read before the American Association for the 1 Advancement of Science last August, I described certain experiments made by Mr. Sumner Tainter and myself which had resulted in the construction of a "Photophione," or apparatus for the production of sound by light $\dagger$; and it will be my object today to describe the progress we have made in the investigation of photophonic phenomena since the date of this communication.

In my Boston paper the discovery was announced that thin disks of very many different substances emitted sounds when exposed to the action of a rapidly-interrupted beam of sunlight The great variety of material used in these experiments led me to believe that sonorousness under such circumstances would be found to be a general property of all matter.

At that time we had failed to obtain audible effects from masses of the various substances which became sonorous in the condition of thin diaphragms ; but this failure was explained

* From advance proofs of a paper read before the National Academy of Arts and Sciences, A pril 21, 1881, communicated by the Author.

† Proceedings of the American Association for the Advancement of Science, August 27th, 1880; see, also, American Journal of Science, vol. xx. p. 305 ; Journal of the American Electrical Society, vol. iii. p. 3 ; Journal of the Society of Telegraph Engineers and Electricians, vol. ix. p. 404 ; Annales de Chimie et de Physique, vol. xxi. 